\title{
Stress fractures of the lumbar spine in cricketers: A suggested rehabilitation programme post surgery
}

Vijai Ranawat*

Consultant Orthopaedic Surgeon, Department of Trauma and Orthopaedics, Harrogate and District NHS Trust Lancaster Park Road, Harrogate, HG2 7SX, North Yorkshire, UK

Stress fractures of the pars interarticularis of the lumbar spine in professional fast bowlers have become commonplace in recent times [1]. Orchard \& James have reported the prevalence to be $16.1 \%$ in a study assessing injuries in professional pace bowlers over a four-year period [2]. Immense strains are placed on the lumbar spine due to the repetitive combined movements of hyperextension, lateral flexion, thoracolumbar rotation and an impact force that occurs when the bowler lands in his delivery stride [3-5]. This complex movement of bowling is repeated between 142-235 per week for an average professional bowler [6]. Modern professional cricketers also play for 12 months in a year [4] and so it is hardly surprising that young fast bowlers may develop stress fractures of the lumbar spine [7]. Many are lost to the game with back pain [8] and their return to sport involves a long period of treatment.

These stress fractures can be managed conservatively by a combination of rest, supervised rehabilitation, bowling action analysis and re-training to a 'safe' action. Ranawat, et al. report returns to professional sport in 8 players out of a group of 18 players with confirmed pars interarticularis stress fractures treated by these conservative means [4]. Those players who responded to conservative measures were a group comprised of medium pace/spin bowlers and batsmen. Surgery was considered in those players who did not respond to these conservative measures and this group essentially compromised of the fast bowlers. Surgery by Buck's direct repair of the pars lesion [9] gave very good results (Figure $1 \& 2$ ) enabling 12 fast bowlers to return to professional sport at an average follow-up of over 5 years and two of this group having over 10 years follow-up and 4 playing internationally [4].

Buck's direct repair is an open surgical technique that exposes the affect lumbar pars interarticularis via a midline incision and blunt elevation of paraspinal soft tissues. The defect is debrided and filled with bone graft. A single bone screw traverses the defect (Figure 3).

Postoperative rehabilitation is of the utmost importance following surgery to this group [4] and a suggested programme has been developed and is outlined.

\section{Rehabilitation programme}

Exercises and rehabilitation should proceed at a rate that is proportional to graft incorporation at the operative site. The key functional goal is a return to pace bowling at 6 months after surgery though not necessarily competition.

The process of rehabilitation is an interdisciplinary approach requiring the input and direction from surgeon, physiotherapist, trainer, cricket administrator, coach, biomechanist, podiatrist, sports

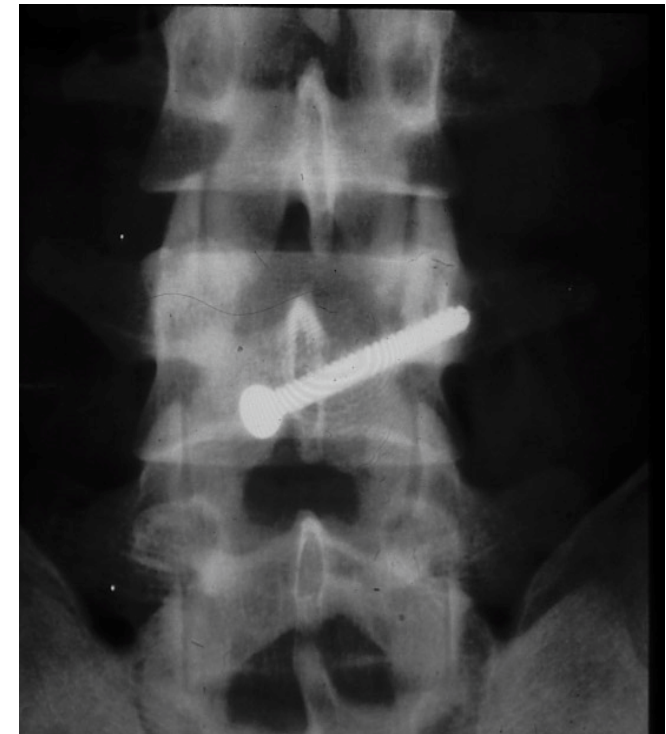

Figure 1. AP X-Ray of lumbar spine demonstrating Buck's repair of Right L4 Pars interarticularis defect.

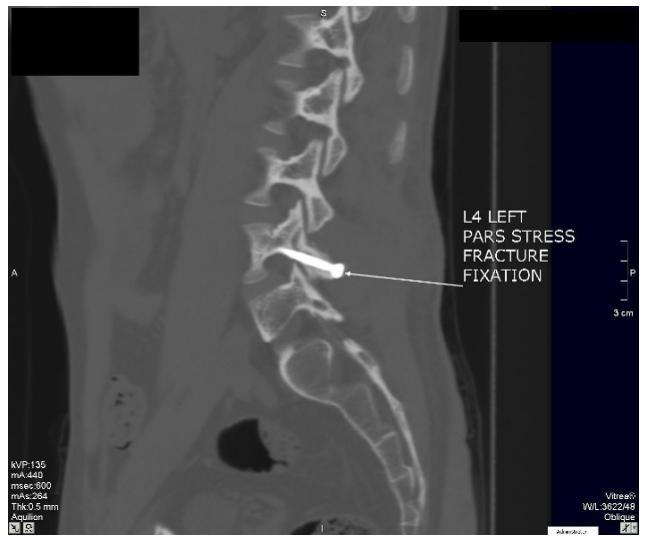

Figure 2. Sagittal CT Scan demonstrating screw position of Buck's repair.

Correspondence to: Vijai Ranawat FRCS(Orth), Consultant Orthopaedic Surgeon, Department of Trauma and Orthopaedics, Harrogate and District NHS Trust Lancaster Park Road, Harrogate, HG2 7SX, North Yorkshire, UK, E-mail: vijairanawat@hotmail.com

Received: April 22, 2018; Accepted: April 30, 2018; Published: May 09, 2018 


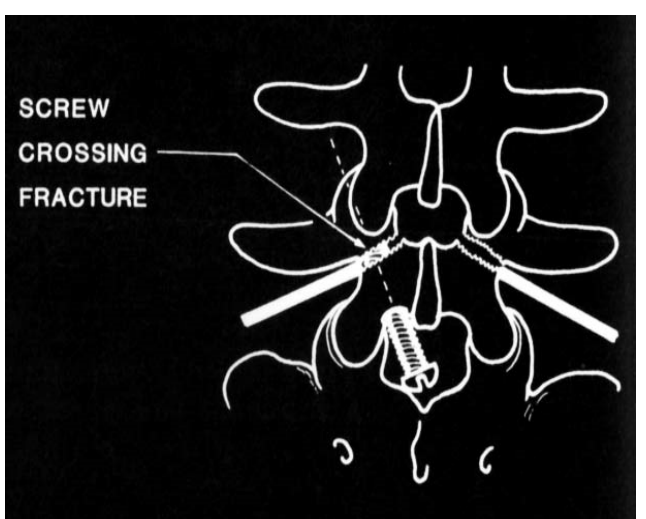

Figure 3. Diagrammatic representation of Buck's repair.

physician, and nutritionist. This time is also utilised to deal with other areas that may have been ignored during competition.

The rehabilitation process can be divided into 7 stages:

\section{Stage 1: Surgery}

Stage 2: Recovery from surgery and commencement of rehabilitation

Stage 3: Return to sport specific training

Stage 4: Continued training with bowling added (for a minimum of 4 weeks)

Stage 5: Bowling at intensity in club games (for 4-6 weeks - the criteria to proceed is being comfortable bowling without restriction with a stable action and being able to produce pace in spells)

Stage 6: Bowling at provincial/county/state level (as above and being able to produce paced spells consistently over 2-4 weeks)

\section{Stage 7: Return to international level competition.}

Immediately post surgery the patient wears a brace and is advised to rest for 2 weeks until the wound has healed. The rehabilitation programme starts at this stage with education, goal setting and a home exercise program of isometric trunk exercises and walking.

Education consists of developing an understanding of the longterm management of bowling related low back pain including a review of bowling action.

Over the next 4 to 6 weeks the rehabilitation goal is to prevent de-conditioning. No load should be placed on the spine. Non-spinal stressing cardiovascular exercise (such as exercise bicycle) for up to 60 minutes per day is permitted as is gentle weight training for the lower body. Hydrotherapy can also be considered at this stage. A normal stretching regime and also a light Swiss ball workout for trunk stability maintains flexibility and core strength.

Stage 3 commences at this point for next 4 to 6 weeks. This sees further strengthening work and a return to cricket specific exercises. Load can start to be placed upon the spine and gently increased as tolerated. Cardiovascular work continues and includes a progression from light running to jogging (with brief running spells on grass) and eventually to sprinting. Further weight training to the lower body continues in magnitude and endurance work is added in by increasing repetitions. Trunk work and stretching can progress further. Static cable bowling and walked through bowling action can start now.

For the first 3-4 months the physiotherapist works closely with the surgeon in determining and leading the programme for the player. When the physiotherapist is confident of the player beginning further training, he discharges the player to the trainer. This has the psychological effect of reinforcing to the player that he is progressing through his, at times, long rehabilitation and confirms that it is the trainer who is now responsible for his programme.

At approximately four months post surgery, technique bowling can commence under the supervision of a bowling coach. The bowling action is carefully scrutinised as it has been shown that there is a high incidence of low back pain associated with mixed actions [5]. The bowling load is gradually built up with action adjustment as necessary for two months. At this stage, if all is progressing well, bowling can commence in club matches. Over the next 4-6 weeks, if bowling without restriction with a stable action is comfortable, first class domestic competition can be entered. If bowling at pace is comfortable over the next 2 to 4 weeks the bowler can proceed to international competition.

Throughout the rehabilitation programme, as the bowling loads are increased, the supplementary training is reduced in order to reduce the overall physiological demands on the player. Bowling loads are determined based upon the player's historical bowling loads per week. Furthermore, the role of rest from bowling is also important in returning to bowling at the highest level [6].

There is a certain pressure for rapid rehabilitation in order to return the player back to professional sport in the shortest possible time both in non-operative and operative management of this condition. Bowling action analysis and retraining from the 'mixed' action which is very commonly associated with this injury $[1,3,4,5,10]$ forms a key part of the rehabilitation programme and the role of the bowling coach and trainer is stressed.

If surgery is undertaken, a postoperative rehabilitation program that involves graduation of exercises in line with incorporation of the bone graft to the pars lesion is essential. The team approach to this rehabilitation is important and a programme such as the one outlined has seen very good results after surgical treatment of this patient group [4].

\section{References}

1. Hardcastle P, Annear P. Foster DH, Chakera TM, McCormick C, et al. (1992) Spinal abnormalities in young fast bowlers. J Bone Joint Surg Br 74: 421-425. [Crossref]

2. Orchard J, James T (2003) Cricket Australia 2003 injury report. J Sci Med Sport 6 : 520-521. [Crossref]

3. Farfan HF, Osteria V, Lamy C (1976) The mechanical aetiology of spondylolysis and spondylolisthesis. Clin Orthop 117: 40-55. [Crossref]

4. Ranawat VS, Dowell JK, Heywood-Waddington MB (2003) Stress fractures of the lumbar pars articularis in athletes: a review based on the long-term results of 18 professional cricketers. Injury 34: 915-919. [Crossref]

5. Elliott B (2000) Back injuries and the fast bowler in cricket. J Sports Sci 18: 983-991 [Crossref]

6. Dennis R, Farhart P, Goumas C, Orchard J (2003) Bowling workload and the risk of injury in elite cricket fast bowlers. J Sci Med Sport 6: 359-367. [Crossref]

7. Hardcastle P (1993) Repair of spondylolysis in young fast bowlers. J Bone Joint Surg $\operatorname{Br} 75$ : 398-402. [Crossref]

8. Elliot B, Foster D, Blanksby BA (1989) Send the stumps flying-the science of fast bowling. UK: University of WA Press, UK.

9. Buck JE (1970) Direct repair of the defect in spondylolisthesis: preliminary report. $J$ Bone Joint Surg Br 52: 432-437. [Crossref]

10. Elliott B, Khangure M (2002) Disk degeneration and fast bowling in cricket: an intervention study. Med Sci Sports Exerc 34: 1714-1718. [Crossref]

Copyright: (C2018 Ranawat V. This is an open-access article distributed under the terms of the Creative Commons Attribution License, which permits unrestricted use, distribution, and reproduction in any medium, provided the original author and source are credited. 